\title{
PANDANGAN BUNG KARNO TENTANG PANCASILA DAN PENDIDIKAN
}

\author{
Dwi Siswoyo \\ FIP Universitas Negeri Yogyakarta \\ dwi.siswoyo@yahoo.co.id
}

\begin{abstract}
Abstrak: Penelitian ini bertujuan untuk mengetahui hal-hal yang esensial dari pandangan Bung Karno tentang Pancasila dan pendidikan. Metode penelitian historis ini mengkaji karya-karya Bung Karno. Data dianalisis dengan teknik analisis menggunakan pendekatan hermeneutika dialektis untuk memperoleh fusi horison makna tentang Pancasila dan pengembangan pendidikan nasional Indonesia. Hasil penelitian ini dapat memberikan gambaran pandangan tentang urgensi nasionalisme dalam membangun bangsa dan urgensi Pancasila sebagai dasar filosofi negara termasuk sebagai dasar filosofi pendidikan nasional Indonesia, serta urgensi pendidikan nasional dalam membangun kepribadian (karakter) bangsa Indonesia. Pengembangan pendidikan nasional dilakukan menggunakan pendekatan "eklektik-inkorporatif-harmonis-dinamis".
\end{abstract}

Kata Kunci: nasionalisme, pendidikan nasional

\section{BUNG KARNO’S VIEW ON PANCASILA AND EDUCATION}

\begin{abstract}
This study was aimed at finding out Bung Karno's essential view on Pancasila and education. This historical research method examined the philosophical works of Bung Karno. The data were analyzed using the hermeneutic dialectic approach to pick out the meaning horizon fusion on Pancasila and the development of the Indonesian national education. The findings showed a snapshot view of the urgency of nationalism in building the nation and the urgency of Pancasila as the country's basic philosophy including Indonesia's national philosophy of education, as well as the urgency of the national education in building the nation's character. The development of the national education was carried out through the 'eclectic-incorporative-harmonious-dynamic' approach.
\end{abstract}

Keywords: nationalism, national education

\section{PENDAHULUAN}

Dewasa ini dalam dunia pendidikan Indonesia baik dalam teori maupun dalam praktik pendidikan, lebih banyak mengacu pada pandangan tokoh-tokoh Barat, dibandingkan dengan mengacu pada pandangan tokoh-tokoh nasional bangsa Indonesia sendiri. Padahal pandangan tokoh-tokoh asing itu tidak dapat lepas dari pengaruh pandangan tentang filosofi, ideologi, politik, sosio-budaya dan ekonomi yang diyakininya. Dengan perkataan lain kita lebih cebderung gandrung untuk menjadi orang lain dari pada menjadi diri kita sendiri. Di samping itu pendidikan lebih cenderung mengedepankan hal-hal yang bersifat ekonomis-teknis dan kurang hirau dengan hal-hal lebih bersifat fondasional yang memperkokoh gerak langkah pendidikan nasional yang prospektif -antisipatif.

Kita memang gandrung untuk membangun pendidikan, untuk tumbuh dan berubah secara progresif, namun bukan dengan harga setinggi penghancuran eksistensi dan esensi jati diri bangsa sendiri. Kita ingin turut mengenyam dan menyumbang kemajuan ilmu dan teknologi yang spektakuler, namun bukan kemajuan semu yang secara "built-in" mengandung kekalahan total dipandang dari segi nilai-nilai filosofi, nilai-nilai ideologi dan nilai-nilai budaya kita sendiri.

Berdasarkan latar belakang di atas, dipandang penting mengkaji pandangan Bung Karno tentang Pancasila dan pendidikan, selain Bung Karno sebagai penggali Pancasila, juga sangat menekankan urgensi membangun jiwa 
dan karakter bangsa. Jiwa dan karakter bangsa yang ingin dibangun sudah tentu jiwa dan karakter yang Pancasilais sejati. Penelitian ini bertujuan mengkaji pandangan Bung Karno tentang: (1) urgensi nasionalisme dalam membangun bangsa, (2) urgensi Pancasila sebagai dasar filosofi negara Indonesia, (3) urgensi Pendidikan Nasional dalam membangun kepribadian (karakter) bangsa.

\section{METODE}

Metode penelitian ini adalah historis filosofis yang mengkaji karya-karya Bung Karno tentang nasionalisme, pancasila, dan pendidikan. Teknik analisis penelitian ini menggunakan pendekatan hermeneutika dialektis, dengan melakukan berdialog tetrhadap karya-karya Bung Karno untuk memperoleh fusi horison makna tentang nasionalisme, pancasila, dan pendidikan.

\section{HASIL DAN PEMBAHASAN}

\section{Urgensi Nasionalisme dalam Pembangunan Bangsa}

Sukarno lahir pada hari Kamis Pon, tanggal 18 Sapar 1813 tahun Saka, bertepatan dengan tanggal 6 Juni 1901 di Lawang Seketeng, Surabaya dari pasangan Raden Sukemi Sosrodihardjo dan Ida Ayu Nyoman Rai yang lebih dikenal sebagai Idayu. Idayu adalah kelahiran Bali dari kasta Brahmana (keturunan bangsawan). Raja Singaraja yang terakhir adalah paman dari Ida Ayu Nyoman Rai.

Ayah Sukarno, Raden Sukemi Sosrodihardjo berasal dari Jawa, berasal dari keturunan Sultan Kediri. Bagaimana Raden Sukemi menaklukkan hati Idayu, diceriterakanlah kepada Sukarno oleh Ibunya

Sukarno lahir dengan nama Kusno, dan memulai hidup ini sebagai anak yang sakitsakitan. Oleh karena itu, Sang Bapak berpikir bahwa nama Kusno tidak cocok dan harus diberi nama lain supaya tidak sakit-sakitan lagi. Sang Bapak berkata kepadanya, "Kus, engkau akan kami beri nama Karna. Karna adalah salah seorang pahlawan terbesar dalam cerita Mahabarata”. Sambil memegang bahu Kusno dengan kuat sang Bapak memandang jauh ke dalam mata putranya itu. "Aku selalu berdo'a", Sang Bapak menyatakan "agar engkau pun menjadi seorang patriot dan pahlawan besar dari rakyat. Semoga engkau menjadi Karna yang kedua". Nama Karna dan Karno sama saja. Dalam bahasa Jawa huruf "A" menjadi "O". Awalan "Su" pada kebanyakan nama berarti baik, paling baik. Jadi Sukarno berarti pahlawan yang paling baik (Adams, 2007:31-32).

Oleh karena itulah, menurut Sukarno, nama Sukarno menjadi namanya yang sebenarnya dan satu-satunya. Waktu di sekolah tanda tanganku dieja Soekarno-mengikuti cara Belanda. Setelah Indonesia merdeka Sukarno memerintahkan semua "OE" ditulis kembali menjadi "U". Nama Soekarno sekarang ditulis menjadi Sukarno. Akan tetapi, tidak mudah bagi seseorang untuk mengubah tanda tangan setelah berumur 50 tahun, maka dalam hal tanda tangan, Sukarno masish menulis S-O-E. (Adams, 2007:32). Bung Karno meninggal dunia pada 21 Juni 1970.

Oleh karena itu, tulisan-tulisan nama Bung Karno yang masih menggunakan "OE" (Soekarno) perlu diganti dengan "U" (Sukarno). Ini sudah dilakukan dalam karya-karya Bung Karno dengan nama Sukarno dalam bukunya yang berjudul antara lain: Dibawah Bendera Revolusi Jilid I (1963) \& Jilid II (1963), Sarinah (1963), Camkan Panca Sila (1964), dan dalam berbagai pidato kenegaraannya. Kendati hanya perubahan kata (bahasa) dalam penulisan nama, namun hal ini mempunyai kandungan makna yang sangat penting sekali dalam konteks nasionalisme.

Tilaar menyatakan beberapa faktor penting dalam menumbuhkan nasinalisme adalah : (1) bahasa, (2) budaya, dan (3) pendidikan (HAR. Tilaar, 2007:25-26). Sumpah Pemuda 28 Oktober 1928 telah menetapkan bahasa Indonesia sebagai bahasa persatuan, merupakan benarnya ungkapan yang mengatakan "Bahasa menunjukkan bangsa". Bahkan Bung Karno (1928) sendiri pernah manyatakan bahwa nasionalisme kita adalah nasionalisme yang membuat kita menjadi "perkakasnya Tuhan", dan membuat kita menjadi "hidup di dalam 
roh". Nasionalis sejati adalah nasionalis yang nasionalismenya itu bukan semata-mata suatu copie atau tiruan dari nasionalisme Barat, akan tetapi timbul dari rasa cinta akan manusia dan kemanusiaan (Sukarno, 1964:5).

Nasionalisme adalah mesin besar yang menggerakkan dan mengawasi semua kegiatan internasional kita, nasionalisme adalah sumber besar dan inspirasi agung dari kemerdekaan. Nasionalisme di Asia dan Afrika tidaklah sama dengan yang terdapat pada sistem negaranegara Barat. Di Barat, nasionalisme berkembang sebagai kekuatan yang agresif yang mencari ekspansi serta keuntungan bagi ekonomi nasionalnya. Nasionalisme di Barat adalah kakek dari imperalisme yang bapaknya adalah kapitalisme. Di Asia dan Afrika, dan saya kira juga di Amerika Latin, nasionalisme adalah gerakan pembebasan, suatu gerakan protes terhadap imperalisme dan kolonialisme, dan suatu jawaban terhadap penindasan nasionalismechauvinisme yang bersumber di Eropa. Nasionalisme Asia dan Afrika serta nasionalisme Amerika Latin tidak dapat ditinjau tanpa memperhatikan inti sosialnya (Sukarno, 2000: 6061).

Nasionalisme tak dapat diragukan lagi terbukti telah merupakan sebuah kekuatan potensial bagi persatuan dan perkembangan kesadaran baru tentang tujuannya, oleh karena telah membantu menghilangkan kekhawatiran dan ketidakpastian sebagai akibat pergeseran identitas nasional (Soedjatmoko, 1985:161)

Nasionalisme merupakan faktor yang penting dalam pembangunan identitas atau jati diri bangsa.

Mingguan Newsweek (29 Juni 1970), menulis antara lain, telah hilang salah seorang tokoh raksasa dunia masa sesudah penjajahan. Tajuk rencana harian South China Morning Post dari Hongkong yang berjudul "Bung Karno", memberi komentar antata lain bahwa orang yang memimpin Indonesia dari penjajahan ke kemerdekaan tidak ada lagi. Tidak disangsikan, bahwa wafatnya akan disesalkan apa pun kesalahannya. Meskipun Indonesia terdiri atas ribuan pulau dengan penduduk yang mempunyai bahasa yang berbeda-beda adalah jasa- nya, bahwa dia mempersatukan mereka dan merintis jalan untuk satu bangsa, bahasa dan kesetiaan (Siagian, 1988:51).

Harian Hongkong Standard yang terbit di Hongkong, menulis bahwa Bung Karno adalah perintis kebangsaan Indonesia. Apa yang dia perbuat untuk negerinya, tidak ada orang lain dapat berbuat pada waktu negeri itu memerlukan seorang pemimpin. Dia mengisi lowongan itu dengan terpuji. Dia menjadi lambang kebangsaan Indonesia" (Gayus Siagian, 1988). Menteri Dalam Negeri Malaysia, Tun Dr. Ismail, berkata : "Kami semua menyesal wafatnya seorang pemimpin besar, apa pun kesalahannya" (Siagian, 1988:51-52).

Presiden Vietnam Utara, Ton Due Thang menyatakan bahwa Rakyat Asia-Afrika dan umat dunia selamanya akan mengenang Bung Karno, pejuang patriotik Indonesia yang telah menjunjung tinggi solidaritas Asia - Afrika melawan imperalisme dan kolonialisme. Perdana Menteri India, Ny. Indira Gandi, dalam pernyataan dukacitanya menyatakan kehilangannya dunia Afro-Asia dari seorang pemimpin yang paling senior dan terkenal. Perjuangannya melawan kolonialisme dan imperalisme dan untuk kemerdekaan adalah bagian dari sejarah (Siagian, 1988:53).

Dari pernyataan-pernyataan di atas menunjukkan betapa terkenalnya Bung Karno di mata dunia, baik di kalangan para tokoh dunia, tetapi juga di kalangan masyarakat dunia. Bung Karno adalah pemimpin yang kharismatik. Kepopuleran Bung Karno di tingkat nasional maupun internasional, bukan saja dipandang dari kaca mata perjuangannya dalam menentang kolonialisme dan imperalisme dengan penuh patriotik, melainkan juga pandangan-pandangan yang futuristik tentang nasionalisme dunia yang aman, adil, tertib dan damai. Bung Karno dipandang sebagaim tokoh dunia yang berani dan tegas, yang berwawasan nasionalisme- perikemanusiaan. Ini menunjukkan bahwa Bung Karno selain berjuang untuk kepentingan nasional, juga senantiasa berpikir dan berjuang dalam konteks global, dan sikap nasionalisme melampaui batas negara-bangsanya. 


\section{Urgensi Pancasila sebagai Dasar Filosofi Negara}

Pada tanggal 1 Juni 1945, Bung Karno adalah satu-satunya tokoh yang menyampaikan pidato sesuai yang diminta oleh ketua sidang Dokuritsu Zyunbi Tyoosakai tentang dasarnya Indonesia Merdeka, "Philosofische grondslag" daripada Indonesia Merdeka. "Philosofische grondslag" itulah pundamen, filosofi, pikiranyang-sedalam-dalamnya, jiwa, hasrat-yang-sedalam-dalamnya untuk di atasnya didirikan gedung Indonesia Merdeka yang kekal dan abadi (Sukarno, 1964:9). Jadi, tidak satu pun pembicara sebelumnya yang menyampaikan tentang Dasar Indonesia Merdeka

Apakah yang dinamakan merdeka? Pertanyaan ini dijawab sendiri oleh Bung Karno di dalam risalah "Mencapai Indonesia Merdeka" yang pernah ditulisnya pada tahun 1933, dengan dikatakannya bahwa kemerdekaan, politeke onafhankelijheid, political independence, tak lain dan tak bukan ialah jembatan, satu jembatan emas, ... di seberangnya jembatan itulah kita sempurnakan kita punya masyarakat. Di dalam Indonesia Merdeka itulah kita menyehatkan rakyat kita ... Di daalam Indonesia Merdeka kita melatih pemuda kita agar supaya menjadi kuat, di dalam Indonesia Merdeka kita menyehatkan rakyat sebaik-baiknya. Inilah maksud saya dengan perkataan "jembatan". Di seberang jembatan, jembatan emas, inilah kita leluasa menyusun masyarakat Indonesia Merdeka yang gagah, kuat, sehat, kekal dan abadi (Sukarno, 1964:11-15). Philosofische grondslag yang dimaksud oleh Bung Karno adalah Pancasila.

Memang mengingat kejadian-kejadian historis dapat diperbedakan antara beberapa Pancasila, yaitu untuk pertama kalinya istilah Pancasila dipergunakan dalam pidato di BPUPKI pada tanggal 1 Juni 1945, yang kemudian diterbitkan sebagai buku berjudul "Lahirnya Pancasila", Bung Karno mengusulkan dasar filsafat, "philosofische grondslag", "Weltanschaung", di atas mana didirikan Negara Indonesia (Sukarno, 1964:19-34).
Dasar filosofis yang pertama, yaitu Kebangsaan Indonesia, diingatkan Bung Karno bukan satu kebangsaan dalam arti yang sempit, melainkan yang ia kehendaki satu "nationale staat". Bangsa Indonesia, Nasi Indonesia, bukanlah sekedar satu golongan orang yang hidup dengan "kehendak akan bersatu" di atas daerah yang kecil seperti Minangkabau, atau Madura, atau Jogja, atau Sunda, atau Bugis, tetapi bangsa Indonesia ialah seluruh manusiamanusia yang, menurut geopolitik yang telah ditentukan oleh Allah SWT, tinggal di kesatuannya semua pulau Indonesia dari ujung Utara Sumatera sampai ke Irian. "Nationale staat" hanya Indonesia seluruhnya, yang telah berdiri di jaman Sri Wijaya dan Majapahit dan yang kini pula kita harus dirikan bersamasama.

Di malam sebelum Bung Karno akan berbicara di Badan Penyelidik, ia pergi ke luar rumah, kemudian memandangi bintang-bintang di langit. Ia kagum pada ciptaan yang sempurna itu, dan meratap pelan-pelan. Bung Karno menyampaikan kepada Tuhan: "Aku menangis karena besok aku akan menghadapi saat bersejarah dalam hidupku. Dan aku memerlukan bantuan-Mu" (Adam, 2007:240). "Aku tahu, pemikiran yang akan kusampaikan bukanlah milikku. Engkaulah yang membukakannya kepadaku. Hanya Engkaulah yang Maha Pencipta. Engkaulah yang selalu memberi petunjuk pada setiap nafas hidupku. Ya Allah, berikan kembali petunjuk serta ilham-Mu kepadaku" (Adam, 2007:240).

Pada tanggal 1 Juni 1945, di sidang BPUPKI, Bung Karno mengupas kelima mutiara berharga: Kebangsaan, Internasionalisme atau Perikemanusiaan, Demokrasi, Keadilan Sosial dan Ketuhanan Yang Maha Esa, yang kemudian dikenal dengan Pancasila. Bung Karno menjelaskan bahwa hari depan bangsa harus berdasar pada Kebangsaan, karena "orang dan tempat tidak dapat dipisahkan! Tidak dapat dipisahkan rakyat dari bumi yang ada di bawah kakinya" (Adam, 2007:240). Bung Karno menegaskan bahwa, "jangan mengira, bahwa tiaptiap negara-merdeka adalah satu nationale staat!". Kita hanya dua kali mengalami 
nationale staat, yaitu di Zaman Sriwijaya dan di jaman Majapahit... Karena itu, jikalau tuantuan terima baik, marilah kita mengambil sebagai dasar Negara yang pertama: Kebangsaan Indonesia (Sukarno, 1964:22-23).

Kebangsaan Indonesia yang bulat! Bukan kebangsaan Jawa, bukan kebangsaan Sumatra, bukan kebangsaan Borneo, Sulawesi, Bali, atau lain-lain, tetapi kebangsaan Indonesia, yang bersama-sama menjadi dasar atau "nationale staat". ... Memang prinsip kebangsaan ini ada bahayanya. Bahayanya ialah mungkin orang meruncingkan nasionalisme menjadi chauvisme, sehingga berfaham "Indonesia uber Alles". Inilah bahayanya kata Sukarno. Kita bukan saja harus mendirikan negara Indonesia Merdeka, tetapi kita harus menuju pula kepada kekeluargaan bangsa-bangsa. Kita cinta tanah air yang satu, merasa berbangsa yang satu, mempunya bahasa yang satu. Tetapi Tanah Air kita Indonesia hanya satu bahagian kecil saja dari pada dunia! Kita harus menuju pula kepada kekeluargaan bangsa-bangsa" (Sukarno, 1964: 2324). Di Indonesia, inti sosial sebagai pendorong untuk mencapai keadilan dan kemakmuran. Bukankah itu tujuan baik yang dapat diterima semua orang?... Saya bicara tentang seluruh dunia. Masyarakat yang adil dan makmur dapat merupakan cita-cita dan tujuan semua orang (Sukarno, 2000:60-61).

Dasar atau Prinsip filosofis yang nomor dua yang diusulkan oleh Bung Karno adalah "internasionalisme" atau peri-kemanusiaan. Internasionalisme yang dimaksud oleh Bung Karno bukanlah kosmopolitisme, yang tidak mau adanya kebangsaan, yang mengatakan tidak ada Indonesia, tidak ada Nippon, tidak ada Birma, tidak ada Inggris, tidak ada Amerika dan lain-lainnya (Sukarno, 1964:25, 29).

Internasionalisme sama sekali bukan kosmopolitanisme, yang merupakan penyangkalan terhadap nasionalisme. Internasionalisme yang sejati adalah pernyataan dari nasionalisme yang sejati, yaitu setiap bangsa menghargai dan menjaga hak-hak semua bangsa, baik yang besar maupun yang kecil, yang lama maupun yang baru. Internasionalisme yang sejati adalah tanda, bahwa suatu bangsa telah menjadi dewasa dan bertanggung jawab, telah meninggalkan sifat kekanak-kanakan mengenai rasa keunggulan nasional atau rasial. Internnasionalisme yang sejati telah meninggalkan penyakit kekanak-kanakan tentang chauvinisme dan kosmopolitanisme (Sukarno, 2000:62-63).

Internasionalisme tidak dapat hidup subur, kalau tidak berakar di dalam buminya nasionalisme. Nasionalisme tidak dapat hidup subur, kalau tidak hidup dalam taman-sarinya internasionalisme. Jadi dua hal ini bergandengan erat satu sama lain. Kemudian, apakah dasar yang ketiga?

Dasar atau Prinsip filosofis ketiga ialah dasar mufakat, dasar perwakilan, dasar permusyawaratan. Saya yakin, bahwa syarat yang mutlak untuk kuatnya negara Indonesia ialah permusyawaratan, perwakilan. Dalam perwakilan nanti ada perjoangan sehebat-hebatnya. Tidak ada satu staat yang hidup betul-betul hidup, jikalau di dalam badan perwakilannya tidak seakan-akan bergolak mendidih kawah Candradimuka, kalau tidak ada perjoangan faham di dalamnya (Sukarno, 1964:25).

Prinsip ketiga ini disebut oleh Bung Karno, demokrasi, dengan menyatakan: Demokrasi bukanlah monopoli atau penemuan dari aturan sosial Barat, melainkan namun demokrasi tampaknya merupakan keadaan asli dari manusia, meskipun diubah untuk disesuaikan dengan kondisi-kondisi sosial yang khusus (Sukarno, 2000:63). Selama berabad-abad negeri Indonesia hidup dengan kebiasaan asli berupa musyawarah dan mufakat. Ini adalah perundingan demokratis model Asia. Sebagai seorang yang meyakini bahwa kekuatan terletak dalam pemerintahan atas perwakilan, Bung Karno berkata, "Kita tidak akan menjadi negara untuk satu golongan" tetapi "Semua buat semua, satu buat semua, semua untuk satu" (Adam, 2007:241).

Dasar atau prinsip filosofis keempat menurut Bung Karno, yaitu: “... prinsip kesejahteraan, prinsip tidak akan ada kemiskinan di dalam Indonesia merdeka. Jangan saudara kira, bahwa kalau Badan Perwakilan Rakyat ada, kita 
dengan sendirinya sudah mencapai kesejahteraan ini. Negara-negara Eropa dan Amerika ada Badan Perwakilan, ada demokrasi parlementer. Tetapi di Eropa justru kaum kapitalis merajalela. Tidakkah di seluruh benua Barat kaum kapitalis merajalela? Pada hal ada badan perwakilan rakyat. Tak lain tak bukan adalah yang dinamakan demokrasi di Barat itu hanyalah "politieke democratie" saja, sema-mata tidak ada "sociale rechtsvaardigheid", -- bukan keadilan sosial. Kalau kita mencari demokrasi hendaknya bukan demokrasi Barat, tetapi permusyawaratan yang memberi hidup, yakni "politiek-economische democratie" yang mampu mendatangkan kesejahteraan sosial! "(Sukarno, 1964:27-28).

Dasar atau prinsip filosofis kelima menurut Bung Karno dikemukakan sebagai berikut: Saya telah mengemukakan empat prinsip: (1) Kebangsaan Indonesia, (2) Internasionalisme, -- atau perikemanusiaan, (3) Mufakat, -atau demokrasi, (4) Kesejahteraan sosial. Prinsip yang kelima hendaknya menyusun Indonesia Merdeka dengan bertaqwa kepada Tuhan Yang Maha Esa. Prinsip ketuhanan, bukan saja bangsa Indonesia ber-Tuhan, tetapi masingmasing orang Indonesia hendaknya ber-Tuhan Tuhannya sendiri .... Segenap rakyat hendaknya ber-Tuhan secara kebudayaan, yakni dengan tiada "egoisme-agama". Dan hendaknya Negara Indonesia satu Negara yang ber-Tuhan!

Marilah kita amalkan, jalankan agama ..., dengan cara yang b e r k e a d a b a n. Apakah cara yang berkeadaban itu? Ialah $\mathrm{h}$ o $\mathrm{r} \mathrm{m}$ a $\mathrm{t}-$ $\mathrm{menghormat}$ i $\mathrm{s}$ a t u dengan $1 \mathrm{a}$ i $\mathrm{n}$. (Tepuk tangan sebagian hadlirin) ... Marilah kita di dalam Indonesia Merdeka yang kita susun ini, sesuai dengan itu, menyatakan: bahwa prinsip kelima dari pada negara kita, ialah Ketuhan a y a ngberkebuda y a n, Ketuhanan yang berbudi pekerti luhur, Ketuhanan yang hormat-menghaormati satu sama lain. Hatiku akan berpesta raja, jikalau saudara-saudara menyetujui bahwa Negara Indonesia Merdeka berazaskan Ketuhanan Yang Maha Esa (Sukarno, 1964:29-30).

Bung Karno, menegaskan, mengingat bangsa Indonesia meliputi orang-orang berbagai macam agama, namun tetap bersatu, kami menempat Ketuhanan Yang Maha Esa sebagai yang paling utama dalam falsafah hidup kita. Kepercayaan kepada Tuhan Yang Maha Esa merupakan karaktersitik bangsa Indonesia (Sukarno, 2000:58-59).

Sesudah mengemukakan lima sila dari Pancasila di atas, Bung Karno selanjutnya menyatakan bahwa: Saudara-saudara! "Dasardasar Negara" telah saya usulkan. Lima bilangannya. Inikah Panca Dharma? Bukan! Nama Panca Dharma tidak tepat di sini. Dharma berarti kewajiban, sedangkan kita membicarakan dasar. Saya senang kepada simbolik. Simbolik angka pula. Rukun Islam lima jumlahnya. Jari kita lima setangan. Kita mempunyai Panca Indera. Apa lagi yang lima bilangannya? (Seorang yang hadir: Pendawa lima). Pendawa lima-pun lima. Sekarang banyaknya prinsip: kebangsaan, internasionalisme, mufakat, kesejahteraan dan ketuhanan lima pula bilangannya.

Namanya bukan Panca Dharma, tetapi saya namakan petunjuk seorang teman kita ahli bahasa - namanya ialah $\mathbf{P}$ a n c a s i l a. Sila artinya a s a $\mathbf{s}$ atau d a $\mathbf{s}$ a $\mathbf{r}$, dan di atas kelima dasar itulah kita mendirikan Negara Indonesia, kekal dan abadi. (Tepuk tangan riuh). (Sukarno, 1964:30-31).

Bung Karno menyatakan pula keinginannya bahwa Pancasila memiliki fungsi yang melampaui batas-batas nasional: ... saya sungguh-sungguh percaya bahwa Pancasila mengandung lebih banyak daripada arti nasional saja. Pancasila mempunyai arti universal dan dapat digunakan secara internasional... Bangunlah dunia ini kembali! Bangunlah dunia ini kokoh dan kuat dan sehat! Bangunlah suatu dunia di mana semua bangsa hidup dalam damai dan persaudaraan. Bangunlah dunia yang sesuai dengan impian dan cita-cita umat manusia. Putuskan sekarang hubungan dengan masa lampau, karena fajar sedang menyingsing. Putuskan sekarang hubungan dengan masa lampau, sehingga kita bisa mempertanggungjawabkan diri terhadap masa depan (Sukarno, 2000:65-94). 
Adanya isu-isu yang ingin menghilangkan Pancasila sebagai dasar negara, adalah sebuah kemunduran total, yang secara yuridis formal akan membawa kembali negara Indonesia sebelum merdeka. Bung Karno menegaskan bahwa tiga perempat dari permukaan bumi ini, telah dijelajahi, bahkan telah diziarahi ke pula berbagai negara termasuk negara-negara yang umatnya adalah umat Islam. Bung Karno semakin merasa bangga bahwa dasar negara Pancasila itu adalah satu dasar negara yang dikagumi oleh hampir semua bangsa yang telah dikunjungi, terutama sekali oleh umat Islam (Sukarno, 1990:57). Maka, sudah sewajarnya kalau Bung Karno dengan semangat yang berapi tokoh yang sangat gigih dalam mensosialisasikan kehebatan Pancasila.

Apa yang dinyatakan Bung Karno tahun 1960-an, ironisnya masih terjadi akhir-akhir ini. Ia menyatakan: Kejadian-kejadian yang akhirakhir, saudara-saudara, membuktikan sejelasjelasnya bahwa jikalau tidak di atas dasar Pancasila kita terpecah belah, membuktikan dengan jelas bahwa hanya Pancasilalah yang dapat tetap mengutuhkan Negara kita, tetap dapat menyelamatkan negara kita. Negara kita membutuhkan persatuan dan bahwa Pancasila adalah kecuali satu Weltanschauung adalah satu alat pemersatu rakyat Indonesia yang aneka warna ini (Sukarno, 1964: 65).

Tanpa Pancasila negara Indonesia akan tercerai berai tanpa ada tali pengikat rasa kebangsaan Indonesia.

\section{Urgensi Pendidikan Nasional dalam Pem- bangunan Kepribadian (Karakter) Bangsa}

Apa yang dinamakan Bung Karno tentang merdeka, dijawab sendiri oleh Bung Karno dengan menyatakan bahwa kemerdekaan, tak lain dan tak bukan ialah jembatan, satu jembatan emas, yang diseberangnya jembatan itulah disempurnakan masyarakat Indonesia. Disempurnakan dari kata sempurna yang berarti utuh dan lengkap segalanya (tidak bercacat dan bercela (KBBI, 1988:810), dan dalam konteks kehidupan di Indonesia, menyangkut segala bidang kehidupan bermasyarakat, berbangsa dan bernegara. Di dalam Indonesia Merdeka itulah kata Bung Karno perlu disehatkan rakyat Indonesia. Kesehatan,tentu saja meliputi kesehatan fisik, kesehatan jiwa (daya jiwa meliputi akal, rasa dan kehendak) dan kesehatan moralpiritual.

Di daalam Indonesia Merdeka kata Bung Karno perlu dilatih pemuda Indonesia agar supaya menjadi kuat. Berlatih ialah belajar dan membiasakan diri agar mampu (dapat) melakukan sesuatu (KBBI, 1988:502) sesuai dengan kemampuan/keahlian yang dimiliki dan dikembangkan. Di seberang jembatan, jembatan emas, inilah ada keleluasan menyusun masyarakat Indonesia Merdeka yang gagah, kuat, sehat, kekal dan abadi. Menyusun dalam arti luas mengatur secara baik (KBBI, 1988:875) kehidupan masyarakat Indonesia. Ini semua memerlukan pendidikan. Pendidikan dalam arti luas adalah transmisi dan transformasi pengetahuan (knowledge), nilai-nilai (values) dan ketrampilan-ketrampilan (skills) yan berlangsung di dalam dan di luar sekolah yang berlangsung seumur hidup. Pernyataan Bung Karno itu secara implisit mengandung sifat dwitunggal pendidikan nasional meminjam istilah Notonagoro, yaitu pengembangan kemampuan/keahlian dan kepribadian bangsa Indonesia dalam kesatuan organis, harmonis dan dinamis.

Pancasila sebagai dasar filosofi negara menantang untuk dikaji dari berbagai aspek kehidupan, termasuk dari aspek filosofi pendidikan nasional. Dalam kaitan ini Bung Karno menyatakan: Pancasila yang Tuanku Promotor sebutkan sebagai jasa saya itu sebagai ciptaan saya itu, bukanlah jasa saya. Oleh karena saya, dalam hal Pancasila itu, sekadar menjadi "perumus" daripada perasaan-perasaan yang telah lama terkandung-bisu dalam kalbu rakyat Indonesia, -- sekadar menjadi "pengutara" daripada keinginan-keinginan dan isi-jiwa bangsa Indonesia turun-temurun (Bung Karno, 2006:46-47).

Memang benar bahwa Pancasila yang rumusannya secara resmi dan syah menjadi dasar filosofi Negara Kesatuan Republik Indonesia adalah Pancasila yang tercantum dalam Pembukaan UUD 1945, dan hal ini dinyatakan oleh Bung Karno. Pancasila yang tercantum dalam 
Pembukaan UUD 1945 yaitu: Ketuhanan Yang Maha Esa, Kemanusiaan yang adil dan beradab, Persatuan Indonesia, Kerakyatan yang dipimpin oleh hikmat kebijakasanaan/perwakilan, dan Keadilan sosial bagi seluruh rakyat Indonesia.

Namun, Bung Karno juga menyatakan perannya terhadap Pancasila itu adalah bahwa: ... saya menganggap Pancasila itu telah lama tergurat pada jiwa bangsa Indonesia. Saya menganggap Pancasila itu corak karakternya bangsa Indonesia... Telaahlah siapa yang mau menelaah: bangsa Indonesia yang bertema sentral kepada yang lima itu. Berwatak watak yang lima itu, berkepribadian kepribadian yang lima itu, beroman-muka roman-muka yang lima itu. Maka saya bertanya adakah saya berjasa melihat roman-muka Ibuku sendiri, dan lantas mengatakan bagaimana roman-muka Ibuku itu? (Bung Karno, 2006:47-48).

Dasar atau prinsip filosofis yang pertama yaitu Kebangsaan Indonesia, diingatkan Bung Karno bukan satu kebangsaan dalam arti yang sempit, melainkan yang ia kehendaki satu "nationale staat". Bangsa Indonesia, nasi Indonesia, bukanlah sekedar satu golongan orang yang hidup dengan "kehendak akan bersatu" di atas daerah yang kecil, tetapi bangsa Indonesia ialah seluruh manusia-manusia yang, menurut geopolitik yang telah ditentukan oleh Allah SWT, tinggal di kesatuannya semua pulau Indonesia dari ujung Utara Sumatera sampai ke Irian. Pernyataan Bung Karno ini secara edukatif terkandung pentingnya pendidikan Bhinneka Tunggal Ika, atau dalam lingkup yang lebih sempit pendidikan multikultural atau pluralisme dalam mewujudkan persatuan dan kesatuan bangsa.

Bung Karno juga mengingatkan bahwa kita jangan berkata, bahwa bangsa Indonesia yang terbagus dan termulya, serta meremehkan bangsa lain, dan kita harus menuju pula kepada kekeluargaan bangsa-bangsa. Internnasionalisme yang sejati adalah tanda, bahwa suatu bangsa telah menjadi dewasa dan bertanggung jawab, telah meninggalkan sifat kekanak-kanakan mengenai rasa keunggulan nasional atau rasial, telah meninggalkan penyakit kekanak-kanakan tentang chauvinisme dan kosmopolitanisme.
Dasar atau Prinsip filosofis yang nomor dua yang diusulkan oleh Bung Karno adalah "internasionalisme" atau peri-kemanusiaan. Internasionalisme yang dimaksud oleh Bung Karno bukanlah kosmopolitisme (Sukarno, 1964:25, 29).

Internasionalisme sama sekali bukan kosmopolitanisme, yang merupakan penyangkalan terhadap nasionalisme, yang antinasional dan memang bertentangan dengan kenyataan. Internasionalisme yang sejati adalah pernyataan dari nasionalisme yang sejati, di mana setiap bangsa menghargai dan menjaga hak-hak semua bangsa, baik yang besar maupun yang kecil, yang lama maupun yang baru. Internasionalisme yang sejati adalah tanda, bahwa suatu bangsa telah menjadi dewasa dan bertanggung jawab, telah meninggalkan sifat kekanak-kanakan mengenai rasa keunggulan nasional atau rasial, telah meninggalkan penyakit kekanak-kanakan tentang chauvinisme dan kosmopolitanisme (Sukarno, 2000:62-63).

Internasionalisme tidak dapat hidup subur, kalau tidak berakar di dalam buminya nasionalisme. Nasionalisme tidak dapat hidup subur, kalau tidak hidup dalam taman-sarinya internasionalisme. Jadi, dua hal ini bergandengan erat satu sama lainInternasionalisme tidak dapat hidup subur, kalau tidak berakar di dalam buminya nasionalisme dan nasionalisme tidak dapat hidup subur, kalau tidak hidup dalam taman-sarinya internasionalisme. Pernyataan Bung Karno ini secara edukatif terkandung pentingnya pendidikan internasional dalam mewujudkan perdamaian dunia. Pendidikan internasional menurut Barnadib (1988:3) ialah usaha dalam forum internasional untuk mewujudkan harmoni dan perdamaian dunia melalui pendidikan.

Dasar atau Prinsip filosofis ketiga ialah dasar mufakat, dasar perwakilan, dasar permusyawaratan. Dalam perwakilan nanti ada perjoangan sehebat-hebatnya. Tidak ada satu staat yang hidup betul-betul hidup, jikalau di dalam badan perwakilannya tidak ada perjoangan faham di dalamnya. Prinsip ketiga ini disebut oleh Bung Karno, demokrasi, dengan menyatakan: Demokrasi bukanlah 
monopoli atau penemuan dari aturan sosial Barat, melainkan namun demokrasi tampaknya merupakan keadaan asli dari manusia, meskipun diubah untuk disesuaikan dengan kondisikondisi sosial yang khusus. Pernyataan Bung Karno itu secara implisit mengandung makna pentingnya pendidikan berdemokrasi bagi bangsa Indonesia.

Dasar atau prinsip filosofis keempat menurut Bung Karno, yaitu prinsip kesejahteraan, prinsip: tidak akan ada kemiskinan di dalam Indonesia merdeka. Bung Karno menyatakan bahwa kalau kita mencari demokrasi hendaknya bukan demokrasi Barat, tetapi permusyawaratan yang memberi hidup, yang mampu mendatangkan kesejahteraan sosial! Pernyataan Bung Karno menunjukkan bahwa prinsip kesejahteraan sosial adalah prinsip keadilan sosial. Ini mengandung makna bahwa pembangunan di segala bidang kehidupan termasuk bidang pendidikan, keadilan adalah sebuah keniscayaan.

Prinsip yang kelima menurut Bung Karno hendaknya menyusun Indonesia Merdeka dengan bertaqwa kepada Tuhan Yang Maha Esa, yang masing-masing orang Indonesia hendaknya ber-Tuhan Tuhannya sendiri, dengan mengamalkan, menjalankan agama secara yang berkeadaban. Berkeadaban berarti berbudi pekerti luhur, hormat-menghormati satu dengan lain. Bung Karno, menegaskan pula bahwa mengingat bangsa Indonesia meliputi orangorang berbagai macam agama, namun tetap bersatu, dengan menempatkan Ketuhanan Yang Maha Esa sebagai yang paling utama dalam falsafah hidup bangsa. Kepercayaan kepada Tuhan Yang Maha Esa merupakan karaktersitik bangsa Indonesia.

Pidato Bung Karno di muka Sidang Umum PBB Ke XV tanggal 30 September 1960, antara lain menyatakan: Kitab Suci Islam, Qur'an, Surat Al Hjuraat: 13, mengamanatkan: "Hai sekalian manusia, sesungguhnya Kami telah menjadikan kamu sekalian dari seorang lelaki dan seorang perempuan, sehingga kamu berbangsa-bangsa dan bersuku-suku, agar kamu sekalian saling kenal-mengenal satu sama lain. Bahwasanya yang lebih mulia di antara kamu sekalian, ialah siapa yang lebih taqwa kepadaKU".

Pernyataan Bung Karno itu, menunjukkan dengan tegas bahwa bangsa Indonesia pada hakikatnya adalah bangsa yang religius. Ini juga secara yuridis formal tertuang dalam Pancasila yang termuat dalam Pembukaan UUD 1945 pad sila pertama: Ketuhanan Yang Maha Esa. Bung Karno secara pribadi menuturkan pula dalam sebuah buku Cindy Adam (Adam, 2007) bahwa pada malam sebelum berbicara di Badan Penyelidik, pergi ke luar rumah, memandang bintang-bintang di langit, kagum akan ciptaan yang sempurna itu, sambil meratap pelan, menangis pada Tuhan karena besok ia akan menghadapi saat bersejarah dalam hidupnya, yang memerlukan bantuan-Nya. Bung Karno menyatakan: "Aku tahu, pemikiran yang akan kusampaikan bukanlah milikku. Engkaulah yang membukakannya kepadaku. Hanya Engkaulah yang Maha Pencipta. Engkaulah yang selalu memberi petunjuk pada setiap napas hidupku. Ya Allah, berikan kembali petunjuk serta ilham-Mu kepadaku" (Adam, 2007:240).

Pernyataan ini mengandung sebuah komitmen religius, dan komitmen ini dapat semakin ditumbuhkan dengan pendidikan Agama, pendidikan religius. Bung Karno menyatakan pula bahwa: Dan .... entah ini dimengerti orang atau tidak .... saya mencintai sosialisme, oleh karena saya berTuhan dan menyembah Tuhan. Saya mencintai sosialisme, oleh karena cinta kepada Islam. Saya mencintai sosialisme dan berjoang untuk sosialisme itu, malahan sebagai salah satu ibadah kepada Allah. Di dalam cita-cita-sosialku aku ini sosialis, di dalam cita-cita sukmaku aku ini sama sekali theis. Sama sekali pecaya kepada Tuhan, sama sekali ingin mengabdi kepada Tuhan (Sukarno, 1963: 325).

Bung Karno juga menyatakan penting peran pemimpin, guru dalam berbagai bidang kehidupan. Di masa kebangunan, maka sebenarnya tiap-tiap orang harus menjadi pemimpin, menjadi guru. Pahlawan politik menjadi gurunya massa yang mendengarkan pidato-pidatonya dan mengikut pimpinan taktik perjuangannya, journalist menjadi gurunya pembaca- 
pembaca surat kabarnya, bedrijfsleider menjadi gurunya pegawai-pegawai yang di bawahnya, mas lurah menjadi gurunya masyarakat desa yang di bawah pengawasannya, tukang kopi menjadi gurunya anak-isteri yang membantu pekerjaannya, -- semua yang menjadi gurunya semua orang. Alangkah haibatnya dan alangkah bijaksananya, waktu Nabi Muhammad S.a.w baersabda: "Semua kamu itu adalah pemimpin dan akan diperiksa dari hal pimpinannya" (Sukarno, 1964: 611).

Ini sebuah pernyataan bahwa semua orang, karena guru (pemimpin) atau pendidik dalam arti luas, yang mengemban amanah untuk mendidik seseorang atau seseorang yang kebetulan hadirnya berkelompok (kelas, asosiasi, organisasi, profesi, warga, masyarakat dsb.) sekaligus mengemban amanah mendidik dirinya sendiri untuk menjadi teladan.

Alangkah nasionalnya, kalau tiap-tiap gurunya bukan saja memenuhi syarat-syarat "technisch" yang orang biasanya tuntutkan dari seorang guru, tapi benar-benar Rasul Kebangunan yang sejati, --- Rasul Kebangunan bukan saja secara "formeel", tetapi Rasul Kebangunan di dalam tiap-tiap sepak terjangnya, di dalam segenap levenshoundingnya, di dalam sekujur badan dan tulangsungsumnya, --- satu Rasul Kebangunan sampai keujung tiap-tiap getaran rohnya dan jiwanya (Sukarno, 1964: 613).

Berhubung dengan itu, para pendidik utama harus memiliki sifat antara lain: (1) cinta kepada peserta didik, (2) kesadaran akan tugasnya sebagai panggilan Tuhan, (3) rasa wajib melaksanakan tugas diserta rasa tanggung jawab atas kebahagiaan peserta didik (Brodjonagoro,196).

Hanya guru yang benar-benar Rasul Kebangunan dapat membawa anak ke dalam alam Kebangunan . Hanya guru yang dadanya penuh dengan jiwa Kebangunan dapat "menurunkan" Kebangunan ke dalam jiwa anak. ... Guru yang sifat hakikatnya hijau akan "beranak" hijau, guru yang sifat hakikatnya hitam akan "beranak hitam", guru merah akan "beranak" merah.... Tidak, guru tidak bisa "main kumidi", guru tidak bisa mendurhakai ia punya jiwa sendiri. Guru hanyalah dapat mengasihkan apa dia itu sebenarnya (Sukarno, 1964:614615).

Sesuatu bangsa mengajar dirinya sendiri! Sesuatu bangsa hanyalah dapat mengajarkan apa yang terkandung di dalam jiwanya sendiri! Bangsa orang-merdeka akan mendidik anakanaknya menjadi orang-orang yang merdeka (Sukarno, 1964:615).

Karena itu hai Bangsa Indonesia!, dalam revolusi kita ini, janganlah kita mencari kepeloporan mental pada orang lain. Carilah kepeloporan mental itu pada diri kita sendiri. Cari sendiri konsepsi-konsepsimu sendiri! ...jadilah Bangsa yang Besar yang tidak menjiplak, jadilah mercu-suar yang gemilang bersinar sendiri, susunlah kita punya konsepsikonsepsi atas dasar dilektik Revolusi kita sendiri. Freedom to be free, freedom to be free, -- freedom to be free juga di alam konsepsi sendiri! Dan dengan dialektik kita itu, selalu tingkatkanlah konsepsi-konsepsi Revolusi kita itu menjadi setingkat dan seirama dengan dialektikanya Sejarah Umat Manusia yang sekarang juga sedang bergelora dan berbangkit. Jikalau tidak, kita nanti diganyang, dilindas menjadi glepung oleh dialektikanya Sejarah Umat Manusia itu (Sukarno, 1965: 594).

Hal ini menuntut adanya usaha membangun dan mengembangkan Konstruk Filosofi Pendidikan Nasional Pancasila yang dapat digunakan sebagai sumber pangkal dalam dan atau dari pendidikan nasional Indponesia. Usaha ini dapat menggunakan pendekatan "eklektik-inkorporatif-harmonis-dinamis".

Notonagoro menyebut pengembangan filosofi pendidikan nasional Pancasila dengan menggunakan pendekatan "eklektis-inkorporasi” (Notonagoro, 1973:19). Eklektis ialah bersifat memilih yang terbaik dari berbagai sumber (sources) (KBBI,1988:220) dari satu tokoh atau lebih, atau dari satu aliran (teori) atau lebih. Inkorporasi ialah "to include as apart" atau "to combine into a unifide whole" (Webster's Dictionary, 1993:238).

Pendekatan "eklektis-inkorporasi" ialah pengembangan dan pemerkayaan filosofi pendidikan nasional Pancasila dari berbagai unsur 
filosofi/filosofi pendidikan asing asalkan sesuai atau tidak bertentangan dengan kepribadian bangsa yang kita bangun. "Harmonis" artinya "forming a pleassing or consistent whole". Proses eklektis-inkorporasi-harmonis ini dilakukan secara dialektik-dinamik-antisipatif-reflektif-rejuvenatif sehingga pendidikan nasional yang dibangun senantiasa dapat menjawab tantangan zaman.

Dialektika yang berasal dari perkataan yunani "dia" dan "legein", berarti percakapan ("discourse") (Runes, 1974: 78) atau "the art of confensation" (Hall, 1967:385). Pada zaman Yunani kuno, dialektika diartikan sebagai suatu bentuk pemikiran yang dijalankan melalui pertanyaan dan jawaban (Honderich, 1995:198).

"Dialectic is basically an attempt to discover the truth about something using critical reasoning ...". Dialektika merupakan pendekatan fundamental yang melandasi penyingkapan realitas sehingga terjadi fusi horizon tentang kebenaran yang menggungkapkan diri.

Dinamik berarti "of force producing motion (as opposed to static), having force of character", atau "penuh semangat dan tenaga sehingga cepat bergerak dan mudah menyesuaikan diri dengan keadaan dsb" (KBBI,1988:206) sehingga senantiasa bersifat progresif. Antisipatif, artinya bersifat tanggap terhadap sesuatu yang sedang (akan) terjadi (KBBI,1988: 43); "to notice what needs doing and take action in advance", atau "to look forward; to act in action" (Webster's Dictionary, 1993:23) sehingga senantiasa dimiliki pandangan yang visioner. Reflektif, artinya pemandangan atas diri sendiri (Driyarkara, 2006:28) untuk memegang kejernihan intelektual dan tanggung jawab moral (Madison, 1988:90-91) dilakukan melalui pemikiran yang mendalam sehingga ditemukan yang hakiki. Rejuvenatif, artinya "pemudaan kembali” (Sukarno, 1990:187-188) secara konsepsional, dan keyakinan yang kuat akan keberhasilan implementasi filosofi pendidikan nasional Indonesia.

Bung Karno juga menyatakan bahwa Bangsa yang besar adalah bangsa yang menghargai jasa-jasa pahlawannya (Pidato Hari Pahlawan 10 Nopember 1960).
Karena itu, maka pagi-pagi kita harus memperbesar dan memperdalam rasa tanggung jawab kita, baik sebagai manusia, maupun sebagai bangsa. Tanggung jawab kepada siapa? Sudah tentu tanggung jawab terhadap kepada bangsa kita sendiri! Dan tanggung jawab terhadap kepada Allah Rabbul-alamin! (Pidato terakhir Bung Karno: Jangan Sekali-kali Meninggalkan Sejarah, 17 Agustus 1966). Tentu saja keahlian adalah perlu! Tetapi keahlian saja, tanpa dilandaskan pada jiwa yang besar, tidaklah mungkin akan mencapai tujuannya. Inilah perlunya, sekali lagi mutlak perlunya! Nation and character Building! (Pidato terakhir Bung Karno: Jangan Sekali-kali Meninggalkan Sejarah, 17 Agustus 1966) (Daras, 2001:31).

Demikianlah amanat Bung Karno sebagai presiden yang senantiasa mengobarkan semangat bagi semua warga bangsa Indonesia dalam membangun bangsa dan negara, dengan menegaskan pentingnya kesatu paduan antara kemampuan/keahlian dan kepribadian dalam membangun manusia Indonesia seutuhnya dan in dapat diupayakan terutama melalui pendidikan nasional. Bung Karno adalah tokoh yang sangat menekankan nilai-nilai yang sangat sangat esensial yang menjadi dasar filosofi bangsa Indonesia, yang menjadi jati diri bangsa Indonesia. Nilai-nilai inilah yang diperjoangkan agar menjelma dalam diri manusia Indonesia. Nilai-nilai inilah yang menjadi kepribadian bangsa Indonesia. Namun Bung Karno bukan tokoh yang menganut faham nasionalisme yang chauvinistik, (nasionalisme yang sempit) melainkan juga internasionalisme (yang melampaui batas-batas nasional) dengan tetap memegang teguh nilai-nilai filosofi bangsa Indonesia yaitu Pancasila. Bahkan Pancasila itu sendiri karena keluhuran nilai-nilai yang dikandungnya dikampanyekan di forum sidang umum PBB.

Pada pidato terakhir sebagai presiden yaitu tanggal 17 Agustus 1966, beliau menekankan nilai pentingnya sejarah, membangun jiwa bangsa, dan membangun karakter bangsa . Ini menunjukkan Bung Karno tetap visioner, bukan reaksioner.seperti yang menggejala dalam kehidupan bangsa kita akhir-akhir ini, termasuk dalam bidang pendidikan. Nilai-nilai dari sila- 
siila Pancasila, yang digali Bung Karno dan ditetapkan sebagai jiwa bangsa Indonesia, melalui pendidikan nasional harus dioptimalkan dalam penanamannya agar terealisasi dalam kehidupan bermasyarakat, berbangsa dan bernegara.

Pernyataan Bung Karno yang mengutip hadits Nabi Muhmmad SAW bahwa semua orang itu pemimpin ("pendidik" atau "guru") yang harus mempertanggungjawabkan atas kepemimpinannya sehingga harus menjadi teladan bagi siapa saja ("peserta didik") dan tidak boleh main "komidi" (dipanggung saja baik tetapi dalam kenyataan hidup berperilaku buruk dan tidak terpuji) adalah sangat perlu diamalkan di negeri kiat ini. Perilaku pemimipin akan lebih banyak diikuti dari pada apa yang dikatkannya. Inilah prinsip yang mengharuskannya sebagai teladan. Produktivitas Bung Karno sendiri dalam berkarya tulis juga patut menjadi teladan.

\section{PENUTUP}

- Nasionalisme yang humanis berperan esensial dalam membangun bangsa dalam konteks nasional maupun global.

- Pancasila yang digali dan dilahirkan Bung Karno, yang mengandung nila-nilai sangat ideal sebagai dasar filosofi, ideologi negara dan pandangan hidup bangsa Indonesia harus benar-benar diupayakan secara cerdas, konsekuen, konsisten, dan tanggung jawab oleh segenap bangsa Indonesia sesuai dengan kapasitasnya masing-masing, demi terwujudnya masyarakat yang religius, humanis, nasionalis, demokratis dan berkeadilan.

- Bangsa Indonesia harus berjuang terus dalam merevitalisasi, mereinovasi, merekonstruksi, merejuvenasi dan mereaktualisasi Pancasila dalam berbagai bidang kehidupan pada umumnya, dan dalam bidang pendidikan nasional pada khususnya da;lam membangun kepribadian (karakter) bangsa.

- Pengembangan pendidikan nasional dilakukan menggunakan pendekatan "eklektik-inkorporatif-harmonis-dinamis”. Proses eklektis-inkorporasi-harmonis ini dilakukan secara dialektik-dinamik-antisipatif-reflektif-rejuvenatif sehingga pendidikan nasional yang dibangun senantiasa dapat menjawab tantangan zaman.

- Untuk keberhasilan pendidikan, pemimpin, pendidik (guru) tidak dapat hanya main "kumidi", melainkan harus menjadi teladan dalam segala aspek kehidupannya.

\section{UCAPAN TERIMAKASIH}

Ucapan terima kasih disampaikan kepada sejawat dan berbagai pihak yang membantu terlaksanakannya penelitian dan penulisan ini. Semoga itu semua menjadi bagian dari amal kebaikan.

\section{DAFTAR PUSTAKA}

Adams, Cindy. 2007. Bung Karno Penyambung Lidah Rakyat Indonesia. (penerjemah: Syamsu Hadi.ed. rev), Yogyakarta: Yayasan Bung Karno \& Media Pressindo.

Barnadib, Imam.1988. Pendidikan Perbandingan. Yogyakarta: Penerbit Andi Offset.

Brodjonagoro, Sutedjo.1966. Pendidikan Nasional. Yogyakarta: FIP-IKIP Yogyakarta.

Daras, Roso. 2001. Aktualisasi Pidato Terakhir Bung Karno: Jangan Sekali-kali Meninggalkan Sejarah.Jakarta:Penerbit PT. Grasindo.

Depdikbud RI. 1988. Kamus Besar Bahasa Indonesia. Jakarta: Departemen Pendidikan dan Kebudayaan Republik Indonesia.

Driyarkara. 2006. Karya Lengkap Driyarkara. A. Sudiardja, dkk (ed). Yogyakarta : Penerbit Kompas, Gramedia \& Kanisius.

Honderich, Ted. 1995. The Oxford to Companion to Philosophy. New York : Oxford University Press.

Madison, G.B. 1988. The Hermeneutics of Postmodernity. Bloomington \& Indianapolis : Indiana University Press. 
Notonagoro. 1973. Pidato Penganugerahan Gelar Doktor Honoris Causa dalam Ilmu Filsafat pada Prof Drs. Notonagoro, S.H. Yogyakarta: Universitas Gadjah Mada Yogyakarta.

Roland, Hall. 1967. "Dialectic" in Paul Edwards (ed). The Encyclopedia of Philosophy. Volume Two. New York: Macmillan Company \& Free Press.

Runes, Dagobert D. 1974. Dictionary of Philosophy. New Jersey: A Littlefield, Adam \& Co.

Siagian, Gayus. 1998. Wasiat Bung Karno. Jakarta : Ketut Mas Agung corporation.

Soedjatmoko. 1985. Etika Pembebasan. Jakarta: LP3ES.

Sukarno. 1973. Filsafat Pendidikan Nasional Pancasila. FIP IKIP Yogyakarta.

Sukarno. 1963. Sarinah. Yogyakarta: Panitia Penerbit Karangan Presiden Sukarno.
Sukarno.1964. Camkan Pancasila: Pancasila Dasar Falsafah Negara. Jakarta : Departemen Penerangan RI.

Sukarno.1964. Dibawah Bendera Revolusi, Jilid Pertama. Jakarta: Panitya.

Sukarno.1965. Dibawah Bendera Revolusi, jilid kedua. Jakarta: Panitya.

Sukarno.1986. Pancasila sebagai Dasar Negara. Jakarta : Penerbit Inti Idayu PressYayasan Pendidikan Sukarno.

Sukarno.1990. Bung Karno dan Islam : Kumpulan Pidato tentang Islam 1953-1966. Jakarta : Penerbit cv. Haji Masagung.

Sukarno.2000. Membangun Dunia Baru (To Build the World Anew). Yogyakarta: Media Pressindo.

Sukarno. 2006. Filsafat Pancasila Menurut Bung Karno. Yogyakarta: Media Pressindo.

Tilaar, HAR. 2007. Mengindonesia: Etnisitas dan Identitas Bangsa Indonesia Jakarta: PT. Rineka Cipta. 